\title{
An Analysis of Concept Mapping Style in EFL Reading Comprehension from the Viewpoint of Paragraph Structure of Text
}

\author{
Banni Satria Andoko*,**, Yusuke Hayashi* and Tsukasa Hirashima*
}

(Received 14 June 2018 and accepted in revised form 27 February 2019)

\begin{abstract}
In language learning contexts, reading comprehension is an important learning activity. In English as a foreign language (EFL) reading comprehension learning, a frequent reading style is the sentence-by-sentence style, in which learners understand the text only as separate sentences, not as a whole structure. This study focuses on the structural understanding of the text and mapmaking the process from the viewpoint of the paragraph. The assumption in this study is that map-making in KB mapping does not follow sentence order but focuses on sets of meanings formed by paragraphs. This study investigates the relation between the mapmaking processes in KB and SB mapping and the paragraph structure of the text.
\end{abstract}

Keywords: English as a foreign language, reading comprehension, concept map, kit-build map

\section{Introduction}

Reading comprehension is an essential yet challenging task in language learning. Reading comprehension in the English as a foreign language (EFL) context is a particular case of reading comprehension; it is a complex, dynamic, multi-componential, and multidimensional task in the learning process. It is a continuous process of multiple interactions between readers' background knowledge in their Mother Language (ML) and the knowledge to which they are exposed in the Target Language (TL) (here, English). The reading comprehension in EFL is the same as ML reading comprehension. However, it is slower and less successful than ML reading ${ }^{(1)}$.

One of the prevailing reading styles in EFL reading comprehension learning activities is the sentence-bysentence style ${ }^{(2)}$, through which learners understand the text only as separated sentences, not as a whole structure $^{(3)}$. Less proficient readers seem to monitor at wordlevel using intra-sentential information, while more proficient readers seem to be able to use inter-sentential information and take a more holistic approach ${ }^{(4)}$.

Concept mapping is one of the strategies used to support reading comprehension, and it has a good effect on the reading comprehension of EFL learners ${ }^{(5,6)}$. It is

*Graduate School of Information Engineering, Hiroshima University, Japan

**Department of Information System, State Polytechnic of Malang, Indonesia a visual representation of knowledge, which can be employed as a learning strategy by learners to find the relationship between what they know and new information $^{(7)}$. Many researchers have confirmed that EFL learners who used concept mapping gained great reading comprehension skills ${ }^{(5,8-10)}$. Also, many studies have proved that concept or semantic mapping techniques can improve learners' reading comprehension because they can understand the text more efficiently through the concept map ${ }^{(7,9,11,12)}$.

The kit-build concept mapping (KB mapping) $\operatorname{method}^{(13,14)}$. enables the learner to create concept maps with given components decomposed from a concept map. This method has the same efficiency as the original concept mapping (hereinafter, scratch-build concept mapping: SB mapping) method for comprehended information in a comprehension test taken just after reading ${ }^{(15)}$. The main difference between SB mapping and $\mathrm{KB}$ mapping is whether the components with which to build concept maps are fully provided for learners or not. In SB mapping, learners basically create nodes and links by themselves, while in $\mathrm{KB}$ mapping, learners build concept maps with only the nodes and links provided.

KB mapping in EFL reading comprehension learning has better efficiency than SB mapping in the recall of understood information as shown by a delayed comprehension test two weeks later ${ }^{(1)}$. Another study shows the analysis of the difference in map-making between $\mathrm{KB}$ and SB mapping ${ }^{(16)}$. While SB mapping indicated a 
tendency to compose propositions sentence-by-sentence - that is, following sentences from the beginning to the end-KB mapping indicated another tendency: The rate at which they deviated from the sentence order in KB mapping was higher than that of SB mapping. It can be considered that KB mapping can facilitate learners having a mental model of the content of the text not based on the order of sentences.

This study focuses on paragraph structure in concept mapping, in contrast to previous studies. One of the essential factors of reading comprehension are paragraphs ${ }^{(17)}$, and there are many strategies for reading comprehension based on paragraphs ${ }^{(11,18)}$. A previous study investigated map-building style in $\mathrm{KB}$ with the parameter of Anagram Distance (AD), that indicates how different the order of map-making is from the order of the sentence in the text. The result shows that KB mapping tends to deviate from the sentence order more than SB mapping. However, it does not show how learners deviate from the sentence order. In this study, we conduct a further analysis of concept mapping from the viewpoint of paragraph structure- concretely speaking, whether learners deviate randomly or in some specific pattern. This is the research question in this study.

The assumption in this study is that $\mathrm{KB}$ mapping facilitates learners in not following the sentence order from the beginning to the end of the text but to focus on sets of meanings formed by paragraphs. If this assumption is correct, $\mathrm{KB}$ mapping will contribute to the facilitation of proficient reading in EFL. To clarify the contribution, this study introduces a new parameter called Paragraph Remaining (PR) to indicate how much the process of mapping remains in the same paragraph. If both $\mathrm{AD}$ and $\mathrm{PR}$ are high, it can be considered that the learner creates his/her map paragraph-by-paragraph based on his/her mental model. On the other hand, if the $\mathrm{PR}$ is not high but the $\mathrm{AD}$ is high, it can be considered that the learner creates his/her map randomly, or not by following the sentence order and paragraph structure in the text. This study investigates the characteristics of SB- and KB mapping in EFL reading comprehension.

The composition of this paper is organized as follows. The next section gives an overview of KB mapping, followed by an explanation of the difference between KB mapping and the original concept mapping, and the relation between $\mathrm{KB}$ mapping and EFL reading comprehension. Section 3 describes the setting and method of the experiment in this study. In the experi- ment, we used the existing KB mapping system ${ }^{(19)}$ without any modification. Section 4 shows and discusses the result. Finally, Section 5 concludes this paper and provides some promises of future research.

\section{Kit-Build Concept Map}

"Kit-Build Concept Map" or "KB map" is an application that adopts the closed-end approach of the concept map.

Concept maps, as defined by Novak, are graphical tools for organizing and representing knowledge. They include concepts that are usually enclosed in circles or boxes of some type, with relationships between concepts indicated through connecting lines linking two concepts. Words on the line, referred to as linking words or linking phrases, specify the relationship between the two concepts ${ }^{(12)}$. The framework of a KB map has the following two characteristics: (A) A concept map-building task is divided into a segmentation task and a construction task, and then the segmentation task is replaced by a recognition task of parts of a concept map that make up a "kit," and (B) a goal map should be prepared as an ideal map that a learner is required to build; the applicable targets of the KB map are restricted, and it requires several additional functions for the learning environment. Therefore, it is necessary to propose an adequate way to use KB maps under these restrictions ${ }^{(13)}$.

Figure 1 illustrates an example of a goal map. Teachers make goal maps as representations of the structure of what they want learners to learn. Figure 2 shows an example of the parts, called a kit. While in general concept map-building learners are required to extract components from learning resources, in $\mathrm{KB}$ map-building learners recognize the parts.

To conduct the required analysis, a new KB map ability was added: recording learners' activity during the map construction activity as LOG data. The result of the LOG data will be calculated and the calculation result processed through statistical analysis to visualize and support this research.

$\mathrm{KB}$ map is an application to support learning that has adopted the Concept Map concept and extended it to a new kind of concept map. KB map includes three main phases: 1) Goal map-building, 2) Learner's mapbuilding, and 3) KB Analyzer. Goal map-building is the phase in which the instructor or teacher constructs a goal map. This created goal map will then be separated 


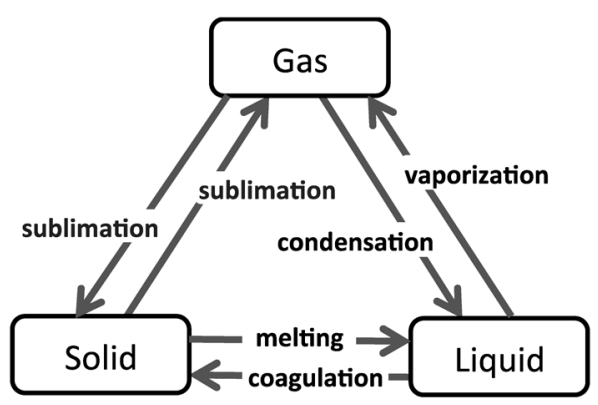

Figure 1. An Example of Goal Map.

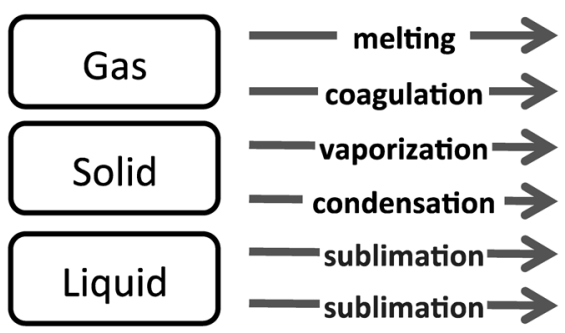

Figure 2. An Example of Kit.

into distinct Nodes and Links that learners will reconstruct in phase 2. The Learner's map is the phase in which learners must construct the provided links and nodes on the learner's map. Learners cannot create, update, or delete nodes or links. They can only make a proposition for provided nodes and links. In phase 3, the teacher or instructor can check the learner's map and analyze it by comparing it to the Goal map.

In this study, we investigated the characteristics of map-making in $\mathrm{SB}$ and $\mathrm{KB}$ with the existing $\mathrm{KB}$ system $^{(18)}$ We used English reading materials and Goal maps made from them. Instructors or teachers were to understand the main idea of the content and then choose or use words from the content or create a new word with the same meaning or purpose for the sentence. For example:

"Any substance may exist as solid, liquid, or gas. If a solid is heated, it will melt to become a liquid. This change is called melting. If the liquid is then cooled, it will freeze to become a solid again. This change is called freezing. Similarly, if a liquid is heated, it will boil to become a gas. This change is called boiling....."

From the reading material, the instructor or teacher constructs a Goal map and separates it into Kits as shown in Figure 1.

\section{Experiment}

\subsection{Procedure}

This experiment involved eight Japanese undergraduate students learning English as a foreign language. The students were divided into two groups by their TOEIC reading scores and used Kit Build (KB) and Scratch Build (SB) in turn. We conducted six sessions with different material each session. In each session, we did several activities, including:

- English group discussion session

- Reading the material session with dictionary and translator allowed

- Constructing a KB map and SB map session with open reading material

- Test session with closed reading material, dictionary, and translator

- Test explanation session

Before the experiment, learners provided their TOEIC scores. Their scores ranged from 900 to 295 , and the TOEIC reading score variation was from 425 to 140. The score variation determined the English competency level of the learners.

\subsection{Materials}

We used six intermediate-level texts in information engineering. The texts had the same word count and, thus, were of the same size. They were taken from Wikipedia and checked for grammatical and semantical errors and for continuity, since we chose sentences selectively. The goal map had already been verified by an English teacher. To support this research, the goal map had to be arranged into a hierarchy map without changing the propositions.

Afterward, we created the corresponding concept map (goal map) for every text by using the Goal Map Editor. The goal map covered the main concepts and relations, and all the goal maps had almost the same size and structure. We prepared comprehension tests, which were multiple choice tests with 10 questions of the same level of complexity. Around $80 \%$ of the comprehension questions could be answered by the goal map, while the others could not. Again, we checked all the materials to 
be sure they did not contain any errors.

\subsection{Anagram Distance}

Anagram Distance (AD) was used to measure the learner's construction style. The style that we were attempting to describe was the sentence-by-sentence style. This style determines that learners construct their map according to the position of the reading material. If the distance result is low, then we can be sure that learners constructed their map according to the position of text in the material. The goal map contains the information on the text position for each proposition. Table 1 shows cases of the calculation of AD. AD measures the difference between the order of proposition-making in concept mapping and the order of sentences related to the propositions in the text. If a learner makes propositions in the same order as the text, $\mathrm{AD}$ is the minimum. Case 1 in Table 1 shows this. On the other hand, the orders are different if AD becomes high. In this study, we use this to measure whether a learner built concept maps sentence-by-sentence.

\subsection{Paragraph remaining}

Paragraph remaining (PR) is also used to measure the learner's construction style. This value measures how often a learner makes propositions continuously

Table 1. Examples of Anagram Distance (AD).

\begin{tabular}{c|cc|cc}
\hline \multirow{2}{*}{ Order } & \multicolumn{2}{|c|}{ Case 1 } & \multicolumn{2}{c}{ Case 2 } \\
\cline { 2 - 5 } & Proposition & Distance & Proposition & Distance \\
\hline 1 & 1 & 0 & 3 & 2 \\
2 & 2 & 0 & 1 & 1 \\
3 & 3 & 0 & 4 & 2 \\
4 & 4 & 0 & 5 & 1 \\
5 & 5 & 0 & 2 & 3 \\
\hline $\mathrm{AD}$ & 0 & & 1.8 & \\
\hline
\end{tabular}

Table 2. Examples of Paragraph Remaining.

\begin{tabular}{c|ccc|ccc}
\hline \multirow{2}{*}{ Step } & \multicolumn{3}{|c|}{ Case 1 } & \multicolumn{3}{c}{ Case 2 } \\
\cline { 2 - 7 } & Paragraph & Possibility & Actual & Paragraph & Possibility & Actual \\
\hline 1 & 1 & & & 2 & & \\
2 & 1 & 1 & 1 & 1 & 1 & 0 \\
3 & 2 & 0 & 0 & 2 & 1 & 0 \\
4 & 2 & 1 & 1 & 2 & 1 & 1 \\
5 & 2 & 1 & 1 & 1 & 0 & 0 \\
\hline PR & 3 & & & 0.33 & & \\
\hline
\end{tabular}

within the same paragraph. This is calculated based on the concept map the learner made and by counting instances of staying within the same paragraph, if possible. For example, in case 2 in Table 2, the learner made two propositions related to the first paragraph and three propositions related to the second paragraph altogether. He first made propositions associated with the second paragraph. Then, he had two options to create a proposition related to the first and second paragraphs, or, possibility 1 in the table. He made the proposition related to the first paragraph, which means he did not make propositions continuously in the same paragraph, so this was not counted in PR. On the other hand, if he had made a proposition related to the second paragraph, it would have been counted in PR. PR is calculated as the division of the count by the possibility to formalize among sessions

\subsection{Result}

Tables 3-5 show the results of the experiment. Here, AD is normalized with the maximum value of each session to compare among sessions. In the comparison between $\mathrm{KB}$ and $\mathrm{SB}$, there is a significant difference only in $\mathrm{AD}$.

\section{Experimental Result and Discussion}

The purpose of this study was to conduct a deeper analysis of map-building styles in SB and KB. In this paper, we analyze map-building style in SB and KB

Table 3. Two-sided $t$-Test Result of Test.

\begin{tabular}{ccc}
\hline Type & Mean $(S D)$ & $p$-Value \\
\hline KB & $0.74(0.19)$ & 0.42 \\
SB & $0.68(0.12)$ & \\
\hline
\end{tabular}

Table 4. Two-sided $t$-Test Result of AD.

\begin{tabular}{ccc}
\hline Type & Mean $(S D)$ & $p$-Value \\
\hline KB & $0.47(0.088)$ & 0.049 \\
SB & $0.33(0.15)$ & \\
& & \\
Table 5. & Two-sided $t$-Test Result of PR. \\
\hline Type & Mean $(S D)$ & $p$-Value \\
\hline KB & $0.72(0.14)$ & 0.20 \\
SB & $0.81(0.13)$ & \\
\hline
\end{tabular}


through the combination of $\mathrm{AD}$ and PR. If both PR and $\mathrm{AD}$ are high, it can be considered that the learner created his/her map paragraph by paragraph based on his/ her mental model. On the other hand, if PR is not high but $\mathrm{AD}$ is high, it can be considered that the learner created his/her map randomly, or by not following both the sentence order and paragraph structure in the text. Furthermore, if $\mathrm{PR}$ is high and $\mathrm{AD}$ is low, that is close to sentence-by-sentence.

Our assumption is that KB mapping enables learners to make maps not just randomly or sentence by sentence but based on their mental model reflecting the paragraph structure. If this is true, in $\mathrm{KB}$ mapping, both $\mathrm{PR}$ and $\mathrm{AD}$ are high.

First, we focus on the significant difference in $\mathrm{AD}$. In the result shown in Table $4, \mathrm{AD}$ in $\mathrm{KB}$ is significantly higher than in $\mathrm{SB}$, which is the same as the previous study ${ }^{(14)}$. That means learners with KB do not tend to construct concept maps according to the order of sentences in the text. As mentioned in the Introduction, less proficient readers seemed to monitor at word-level by using intra-sentential information, showing that learners with $\mathrm{KB}$ have different characteristics from less skilled readers.

Nevertheless, this result does not show that learners with $\mathrm{KB}$ construct concept maps like more proficient readers' reading comprehension. If only $\mathrm{AD}$ is high, this also means that learners may randomly pick up sentences from the texts and make propositions.

To check whether they made propositions randomly or not, we analyzed the paragraph remaining (PR). The result shown in Table 5 does not show there is a significant difference in PR between KB and SB. PR in both $\mathrm{KB}$ and $\mathrm{SB}$ is high, 0.71 and 0.82 . This means learners make propositions in the same paragraph with a possibility of about 70 or $80 \%$ if learners have options to make propositions from several paragraphs.

The combination of the result of $\mathrm{AD}$ and $\mathrm{SR}$ implies different characteristics between $\mathrm{KB}$ and SB. The difference between $\mathrm{KB}$ and $\mathrm{SB}$ is $\mathrm{AD}$. It can be considered that map-building style in SB is close to that of sentence-by-sentence concept map construction because PR is high and AD is low, whereas map-building style in $\mathrm{KB}$ is close to paragraph-by-paragraph concept map creation and does not follow the order of sentences in paragraphs so much because both $\mathrm{PR}$ and $\mathrm{AD}$ are high.

\section{Conclusion}

This study analyzes concept map-building styles in EFL reading comprehension as a comparison between $\mathrm{KB}$ and $\mathrm{SB}$ concept mapping. We conclude that reading style with $\mathrm{KB}$ mapping is closer to that of proficient readers than one with SB mapping. The result shows that $\mathrm{PR}$ is not significantly different, but the $\mathrm{AD}$ of the former is higher than the latter. Although both types of reading pay attention to paragraphs as a unit of meaning, reading with SB mapping tends to follow the text sentence by sentence, while reading with KB mapping tends to organize the meaning of the text independently from the order of sentences.

In future work, it will first be necessary to investigate concept map-building style with a larger number of subjects. Second, the next goal is to design an adaptive support environment for reading comprehension based on the considerations of this research and the implementation of the monitoring function.

\section{References}

(1) Alkhateeb, M., Hayashi, Y., Rajab, T. et al.: "Comparison between Kit-build and Scratch-build Concept Mapping Methods in Supporting EFL Reading Comprehension", Information and Systems in Education,Vol. 14, No. 1, pp. $1-15$ (2015).

(2) Gernsbacher, M. A.: "The Structure-building Framework: What It Is, What It Might Also Be, and Why", in Models of Text Understanding, eds. Britton, B. K. and Graesser, A. C., pp. 289-311. Erlbaum, Hillsdale, NJ (1995).

(3) Grellet, F.: Developing Reading Skills: A Practical Guide to Reading Comprehension Exercises, Cambridge University Press, Cambridge (1981).

(4) Mahmoudi, E.: "Comprehension Monitoring Characteristics and Level of Proficiency: A Study of Iranian EFL Learners", Int'1, J. of English Language Teaching, Vol. 1, No. 2, pp. 64-72 (2014).

(5) Manoli, P. and Papadopoulou, M.: "Graphic Organizers as A Reading Strategy: Research Findings and Issues", J. of Creative Education, Vol. 3, No. 3, pp. 348-356 (2012).

(6) Salehi, A. D., Jahandar, S. and Khodabandehlou, M.: "The Impact of Concept Mapping on EFL Student's Reading Comprehension", Indian J. of Fundamental and Applied Life Sciences, Vol. 3, pp. 241-250 (2013).

(7) Phantharakphong, P. and Pothitha, S.: "Development of English Reading Comprehension by Using Concept 


\section{AN ANALYSIS OF CONCEPT MAPPING STYLE IN EFL READING COMPREHENSION FROM THE VIEWPOINT OF PARAGRAPH STRUCTURE OF TEXT}

Maps", J. of Procedia-Social and Behavioral Sciences, Vol. 116, pp. 497-501 (2014).

(8) Barenholz, H. and Tamir, P.: "A Comprehensive Use of Concept Mapping in Design Instruction and Assessment", J. of Research in Science and Technological Education, Vol. 10, No. 1, pp. 37-52 (1992).

(9) Kalhor, M. and Shakibaei, G.: "Teaching Reading Comprehension through Concept Map", Life Science J., Vol. 9, No. 4, pp. 725-731 (2012).

(10) Nesbit, J. C. and Adesope, O. O.: "Learning with Concept and Knowledge Maps: A Meta-analysis", J. of Review of Educational Research, Vol. 76, No. 3, pp. 413-448 (2006).

(11) Block, E.: The Comprehension Strategies of Second Language Readers. TESOL Quarterly, Vol.20, pp. 463494 (1986).

(12) Novak, J. D. and Cañas, A. J.: "The Theory Underlying Concept Maps and How to Construct and Use Them", Technical Report IHMC Cmap Tools 2006-01 Rev 01-2008 (2008)

(13) Hirashima, T., Yamasaki, K., Fukuda, H. et al.: "Framework of Kit-build Concept Map for Automatic Diagnosis and Its Preliminary Use", J. of Research and Practice in Technology Enhanced Learning, APSCE, Vol.
10, No. 1, pp. 1-21 (2015).

(14) Yamasaki, K., Fukuda, H., Hirashima, T. et al.: "Kit-build Concept Map and Its Preliminary Evaluation”, Proc. of the 18th International Conference on Computers in Education, pp. 290-294 (2010).

(15) Funaoi, H., Ishida, K. and Hirashima, T.: "Comparison of Kit-build and Scratch-build Concept Mapping Methods on Memory Retention", Proc. of ICCE 2012, pp. 539-546 (2012).

(16) Alkhateeb, M., Hayashi, Y., Rajab, T. et al.: "Experimental Evaluation of the KB-mapping Method to Avoid Sentence-by-sentence Map-building Style in EFL Reading with Concept Mapping", Information and Systems in Education, Vol. 15, No. 1, pp. 1-14 (2016).

(17) Thorndike, E.: "Reading as Reasoning: A Study of Mistakes in Paragraph Reading”, Reading Research Quarterly, Vol. 6, No. 4, pp. 425-434 (1971).

(18) Gersten, R., Fuchs, L. S., Williams, J. P. et al.: "Teaching Reading Comprehension Strategies to Students with Learning Disabilities: A Review of Research", Review of Educational Research, Vol. 71, No. 2, pp. 279-320 (2001).

(19) Sugihara, K., Osada, T., Nakata, S. et al.: "Experimental Evaluation of Kit-build Concept Map for Science Classes in an Elementary School", Proc. ICCE 2012, pp. 17-24 (2012). 